\title{
Prevalence of Deep Periodontal Pockets in New Mexico Adults Aged 27 to 74 Years*
}

\author{
Amid I. Ismail, BDS, DrPH† \\ Department of Community Dentistry \\ Facuity of Dentistry \\ McGill University \\ Montréal, Quebec H3A 282
}

Stephen A. Eklund, DDS, DrPH

Brian A. Burt, BDS, MPH, PhD

Program in Dental Public Health

School of Public Health

The University of Michigan

Ann Arbor Mi 48109-2029

James J. Calderone, DDS, DrPH

Health \& Environment Department

State of New Mexico

Santa Fe, NM 87503 this population, do not have deep pockets in the si index teeth examined.

Key Words: gingivitis, periodontal disease, periodontz pockets, epidemiology, oral hygiene

Introduction

A number of recent studies have shown that from 1 . percent to about a third of adults older than 20 year may have advanced periodontal disease (1-6). In th 1980 Iowa Survey of Oral Health (1), where pocke depth measurements were obtained from the six inde teeth used by Ramfjord (7), 20.5 percent of the 84 examinees aged five to 65 years had one or more pock ets $4.0-5.0 \mathrm{~mm}$ deep, and only 1.3 percent had at leas one deep pocket. This finding concurs with a recen study (2) of a selected group of 71 adults (of unreporter race) aged 15 to 100 years, residing in a high-fluorid (2.0-3.0 ppm F) village in South Africa. Out of 1,65 pocket measurements obtained from the mesial, facial distal, and lingual surfaces of the six index teeth o Ramfjord, only eight percent were in the range of 4.0 $5.0 \mathrm{~mm}$, and just 0.5 percent were deep pockets. Othe studies conducted with random samples of adults fron the Netherlands (3), Sweden (6), and Finland (5) als have shown that the prevalence of deep pocketing $i$ only about 10 , eight, and 25.6 percent, respectively Moreover, the few studies available on deep pocketin may indicate that if deep pocketing is present it usuall affects only a few teeth (8).

This brief review of the literature suggests that th majority of adults may not have deep pocketing, an that when deep pocketing is present in the mouth may only affect a few teeth. In this study, pocket-dept] data collected from 372 adults aged 27 to 74 years resid ing in Lordsburg and Deming, New Mexico, will b used to test this hypothesis.
"This study was supported in part by NIDR Contract No. N01-DE32443. A summary of this paper was presented at the 1985 meeting of the American Assiciation of Public Health Dentistry in San Francisco.

tAddress all correspondence to Dr. Ismail 


\section{Study Sites}

Pocket depth measurements were obtained during the course of a study of the effects of severe dental fluorosis on oral health of adults. The main objective of the research project was to compare the oral health status of continuous residents in a community with a water supply containing at least four times the optimal concentration of fluoride and those living in a community with an optimally fluoridated water supply. Two communities in New Mexico, Lordsburg and Deming, were selected because they met these criteria and had sufficient numbers of eligible residents. The fluoride concentration in Lordsburg's water supply has been around $3.5 \mathrm{ppm}$ from the time the earliest measurements were made in the 1930s, while the fluoride concentration in Deming has always been around $0.7 \mathrm{ppm}$, the optimal concentration of fluoride in the drinking water for that area. Further details on the fluoride history of both communities and the study design have been described by Eklund and others (9).

Recruitment of subjects. Recruitment of eligible residents was carried out by local coordinators who had a considerable knowledge of the communities and experience in community organization. The selection process required that the individuals be between the ages of 30 and 65 , were born in their respective communities, had been continuous residents for at least the first six years of their life in the city, and had consumed city water during that time. Individuals who claimed that they met these criteria were asked to participate in the study. Later analysis of the fluorosis status of the residents confirmed that they could indeed be classified as continuous residents of the cities (9). All those who participated in the study gave their informed consent to do so. The recruiters estimated that more than 80 percent of the eligible residents contacted consented to participate in the study.

Examinations were conducted with 194 individuals in Lordsburg and 191 in Deming. The age range was from 27 to 74 years. Eight of those who agreed to participate were edentulous. Four of the dentate participants did not give their birth dates and were excluded from the analysis. One individual requested not to be examined for presence of pockets and therefore was excluded from this analysis. Results are therefore presented for 186 adults in Lordsburg and 186 adults in Deming. Of the 372 included in this analysis, 80.6 percent considered themselves Hispanic Americans, and the others were "white, not of Hispanic origin."

Examination criteria and procedures. During the research project, the following oral conditions were measured: fluorosis, coronal and root caries, attrition, abrasion, gingival recession and bleeding, pocket depth and loss of periodontal attachment, presence of plaque and calculus, and range of mandibular movements (maximum opening, protrusion, lateral movements, overjet, and overbite). The examinees also completed a questionnaire investigating the presence of symptoms of temporomandibular (TM) disorders, demographic characteristics, and use of dental services. Three bitewing radiographs were exposed for each examinee. Data abstracted from the radiographs were not included in this analysis.

Four dental examiners participated in the project, with each examiner measuring different oral conditions. Two examiners (SAE and BAB) consulted with staff at the Department of Periodontics, School of Dentistry, University of Michigan, as part of training for the measurement of pocket depth and loss of periodontal attachment. A training session also was held one month prior to the start of data collection in Lordsburg, New Mexico, during which an epidemiologist from the National Institute of Dental Research trained the examiners in diagnosing fluorosis using Dean's criteria (10). Also, during this session, all four examiners measured the prevalence of the previously mentioned oral conditions in 10 volunteers from Lordsburg using the criteria described in the research plan (9). During the two-week period of actual data collection, the investigators reexamined 29 individuals to assess within-examiner consistency. For measurement of pocket depth, the percent of agreement between the first and replicate

\section{Even after correction for the possible underestimation, about three-fourths of the adults in the two communities remain without advanced periodontal destruction.}

examinations, within a range of one $\mathrm{mm}$, was 90 . The percent of agreement of pocket depth classified according to pocket severity as used in this analysis was over 90 percent. For plaque, gingival bleeding, and calculus, the percent agreements were about 78, 78, and 85, respectively.

The sequence of examination for the oral conditions described in this paper was (a) presence of plaque; (b) gingival bleeding (both were measured by the first examiner, JC); (c) presence of calculus; and (d) pocket depth (conditions " $c$ " and " $d$ " were measured by the fourth examiner, SAE). All measurements of the four conditions were conducted only for the six index teeth of Ramfjord (7). For measuring pocket depth and status of gingival bleeding, the facial and mesiofacial tooth sites of each index tooth were measured, while one tooth score was given when the presence of calculus and plaque was evaluated. The Gingival Bleeding Index of Ainamo and Bay (11) was used to measure gingivitis. Calculus deposits were classified into either supragingival calculus only, or subgingival calculus.

Pocket depth refers to the distance between the free gingival margin and the base of the gingival crevice or pocket (12). In this study, pockets were divided according to depth into (a) 0.0-3.0 millimeter ( $\mathrm{mm}$ ) pockets, or "no pockets"; (b) shallow pockets, when the depth was from 4.0-5.0 millimeters (mm); and (c) deep pockets, when the depth was equal to or deeper than $6.0 \mathrm{~mm}$. A similar division has recently been used by Beck and colleagues (1), Reddy and others (2), and Plasschaert 
and others (3). Data on loss of periodontal attachment measured from the cementoenamel junction to the base of the pocket (7) will not be presented in this study.

The measurement of the four oral conditions was carried out as follows:

\section{Dental plaque}

For measuring the presence or absence of plaque, the examiner first observed the index tooth. If plaque was obvious, the tooth was given a positive score (one). Also, if plaque was visible when the cervical margin was contacted by an explorer, a positive score was given. If these procedures did not reveal the presence of plaque, a zero score was awarded to the tooth.

\section{Gingival bleeding}

Assessment of the presence of gingival bleeding was carried out by running a Hu-Friedy no. 11 periodontal probe in the gingival crevice of the index teeth. The examiner first checked the upper index teeth and returned to check whether there was bleeding at the midpoint of the facial surface and the mesiofacial line angle of the gingival margin. The procedure was then repeated on the lower arch. If bleeding was noticed, the examiner awarded the tooth site a positive score, while if no bleeding was noticed, a score of zero was ascribed.

\section{Calculus}

In assessing the presence of calculus, the examiner first probed using a no. 17 explorer for subgingival calculus on each index tooth. Subgingival calculus was defined as dense hard accumulations below the free gingival margin. If any subgingival calculus was detected, a score of two was called and the examination moved to the next index tooth. If subgingival calculus was not detected, then the examiner proceeded with the visual and tactile inspection for supragingival calculus. Supragingival calculus was defined as hard accumulations coronal to the gingival margin, white or whiteyellow in color and of hard, clay-like consistency.

Pocket depth

A Hu-Friedy no. 11 periodontal probe was used to measure to the nearest $\mathrm{mm}$ the distance from the free gingival margin to the base of the pocket or gingival crevice. The examiner first identified the index tooth (starting with the maxillary right first molar); then the probe, held in a pencil grip, was placed against the enamel surface coronally to the margin of the gingiva so that the angle formed by the working end of the probe and the long axis of the crown of the tooth was approximately 45 degrees. A minimal force was used to pass the probe in an apical direction maintaining contact with the tooth. The angle between the probe and the tooth was decreased slightly when the probe touched the gingiva to avoid pressure on the gingiva. When the probe was inserted in the gingival crevice the angle of insertion was changed to maintain contact with the root surface. The probe was always pointed toward the apex of the tooth or the central axis of a multirooted tooth. When the examiner, while still maintaining the light grasp, felt resistance to the apical movement of the probe he recorded the distance the probe had been inserted using the free gingival margin as a landmark.

The correlation coefficients between pocket depth at each tooth site and loss of periodontal attachment at the site were between 0.65 and 0.82 . All of the shallow or deep pockets identified in this analysis were associated with actual loss of periodontal attachment. Findings of the analysis of the association between pocket depth and loss of periodontal attachment can be obtained from the authors.

Statistical analysis. Two sets of summary data were computed for the purpose of this analysis. The first represented the number of teeth (six in all) or tooth sites (12 in all) with supragingival calculus only, subgingival calculus, plaque, gingival bleeding, and with shallow or deep pockets. The second set of summary data was computed using a simple procedure: each individual was classified according to whether or not he or she had the condition under study.

Comparisons between ages, gender, race, and education groups, and residence in the two cities were first carried out using the mean number of teeth or tooth sites with the different oral conditions. Testing whether the differences observed were due to chance or not was carried out using Student's t-test or analysis of variance with Scheffe's confidence intervals. Comparisons were also carried out on the prevalence data. Testing for statistical significance was assessed using the chisquare test or Fisher's exact probability test (13).

To test the combined effects of several risk factors associated with the probability of concurrently having at least one tooth site with a deep pocket, the logistic regression model was used (14). The regression coefficients from this model estimate the increase in the odds ratio (14), which estimates the increase in the probability of concurrently having deep pockets given the presence of one or more of the risk factors. Statistical significance of the logistic regression coefficients was assessed by comparing the ratio of the coefficient to its standard error with a standard normal distribution (14).

\section{Results}

Mean number of pockets by pocket depth. No differences were found between the residents of the two cities in the mean number of tooth sites with pockets of different depths and in the distribution of adults according to pocket depth (Table 1). Therefore, pocket depth data of the residents of both cities were combined during analysis.

TABLE 1

Mean Number of Tooth Sites per Person (Out of 12 Sites in All) by City of Residence and Pocket Depth, for Those Ages 27 to 74 Years, * Lordsburg and Deming, New Mexico, 1984

\begin{tabular}{lccccc} 
& & \multicolumn{3}{c}{ Pocket Depth in mm } \\
\cline { 4 - 6 } City & $\mathrm{n} \ddagger$ & $0-3$ & $4-5$ & $6+$ \\
\hline Lordsburg, NM & 186 & 10.36 & 0.91 & 0.27 \\
Deming & 186 & 10.68 & 0.74 & 0.22 \\
\end{tabular}

"For a description of the method of selection of residents, see the section "Recruitment of subjects."

tWhen p-values are not presented, the differences are not statistically significant.

$\ddagger \mathrm{n}=$ Number of individuals 
The mean number of tooth sites (out of 12 tooth sites) by age and pocket depth are presented in Table 2 . About 90 percent of the tooth sites had pockets between zero and three $\mathrm{mm}$ in depth. The mean number of tooth sites with no pockets significantly decreased with increasing age, while the mean number of tooth sites with shallow or deep pockets increased with increasing age. The increase was significant only for deep pockets.

The mean numbers of tooth sites by pocket depth and education are presented in Table 3. Those with a formal education less than grade nine had a higher mean number of tooth sites with deep pockets than those who had completed high school or attended college, but the difference was not statistically significant. The number of sites with no pocketing increased significantly with advanced education, while the mean number of tooth sites with shallow pockets decreased significantly with increased education status.

Those who considered themselves Hispanic in both cities did not have a significantly different mean number of tooth sites with deep pockets than other residents. Females did have a significantly lower number of tooth sites with deep pockets.

\section{TABLE 2}

Mean Number of Tooth Sites per Person (Out of 12 Sites in All) by Age and Pocket Depth, for Those Ages 27 to 74 Years, Lordsburg and Deming, New Mexico, 1984

\begin{tabular}{|c|c|c|c|c|c|}
\hline \multirow{2}{*}{$\begin{array}{l}\text { Age Group } \\
\text { in Years }\end{array}$} & \multirow[b]{2}{*}{$\mathrm{n}$} & \multicolumn{3}{|c|}{ Pocket Depth in $\mathrm{mm}$} & \multirow{2}{*}{$\begin{array}{c}\text { Mean No. o } \\
\text { Tooth Sites } \\
\text { Examined }\end{array}$} \\
\hline & & $0-3$ & $4-5$ & $6+$ & \\
\hline $27-46$ & 252 & 10.83 & 0.78 & 0.16 & 11.77 \\
\hline $47-74$ & 120 & $9.85^{*}$ & 0.93 & $0.43 t$ & 11.21 \\
\hline Total & 372 & 10.52 & 0.83 & 0.25 & 11.60 \\
\hline
\end{tabular}

"Mean Number of $0-3$ pockets was significantly higher in those aged $27-46$ years, $p<0.0001$.

tMean number of deep pockets was significantly higher in those aged $47-74$ years, $p<0.013$.

TABLE 3

Mean Number of Tooth Sites per Person (Out of 12 Sites in All) by Education Status and Pocket Depth, for Those Ages 27 to 74 Years, Lordsburg and Deming, New Mexico, 1984

\begin{tabular}{lrccc}
\hline \multirow{2}{*}{$\begin{array}{l}\text { Education by } \\
\text { Grade Completed }\end{array}$} & $\mathrm{n}$ & $0-3$ & $4-5$ & $6+$ \\
\cline { 3 - 5 } & 37 & 9.37 & 1.40 & 0.56 \\
$1-8$ & 73 & 10.26 & 1.00 & 0.21 \\
$9-11$ & 165 & 10.60 & 0.79 & 0.23 \\
12 & 94 & $11.09^{*}$ & $0.53+$ & 0.18 \\
College & 369 & 10.53 & 0.82 & 0.24 \\
Total & & &
\end{tabular}

*The mean number of $0-3 \mathrm{~mm}$ pockets in those with low formal education (less than grade nine) was significantly lower than in those who completed high school or attended college based upon Scheffe's 95 percent confidence interval.

tThe mean number of $4-5 \mathrm{~mm}$ pockets in those with low formal education was higher than in those who attended college (Scheffe's 95 percent confidence interval).
Distribution of the examined individuals by pocket depth. Of the 372 examinees included in this analysis, only 46 individuals ( 12.4 percent) had one or more deep pockets (Table 4). Only 2.1 percent of all pocket measurements demonstrated deep pockets. Shallow pockets were present in 37.6 percent of the examinees, with only seven percent of all pocket measurements demonstrating a depth between 4.0 and $5.0 \mathrm{~mm}$. The percentage of deep pockets significantly increased with increasing age from 8.3 percent between 27 and 46 years, to 20.8 percent in those over 46 years of age.

The distribution of the number of tooth sites in those individuals with at least one deep pocket is presented in Figure 1. Of the 46 individuals with such pockets, 28 had only one tooth site equal to or deeper than $6.0 \mathrm{~mm}$. About 89 percent of those with deep pockets had fewer than four such pockets. Only one individual had 11 of the 12 tooth sites examined with deep pockets.

The mean numbers of $0.0-3.0$ and $4.0-5.0 \mathrm{~mm}$ pockets are presented in Figure 2. In those with less than four tooth sites with deep pockets, over half of the tooth sites were not affected by pocketing.

Deep pockets, calculus, and plaque. The mean numbers of teeth without calculus, the number with supragingival calculus alone, those with subgingival calculus, and those with plaque are presented in Table 5. About 98 percent of the examinees had subgingival calculus on more than one of the six index teeth, and 20.1 percent had at least one tooth with only supragingival calculus. Dental plaque accumulations were found in 67.6 percent of the examinees. Those with deep pockets had a significantly higher mean number of teeth (out of six index teeth) with plaque accumulations. They also had a significantly lower mean number of teeth without calculus.

Deep pockets and gingival bleeding. A significantly higher percentage of those with deep pockets had tooth sites with gingival bleeding than those without such pockets $(p=0.04$, Fisher's exact probability test) (Table 6). Of the 46 individuals with deep pockets, 38 individuals (82.6 percent) had at least one tooth site with gingival bleeding, while 69.9 percent of those without deep

TABLE 4

Number and Percent of Individuals by Pocket Depth and Age, ${ }^{*}$ Lordsburg and Deming, New Mexico, $1984(n=372)$

\begin{tabular}{lcc}
\hline \multirow{2}{*}{$\begin{array}{l}\text { Age Group } \\
\text { in Years }\end{array}$} & \multicolumn{2}{c}{ At Least One Shallow Pocket $t$} \\
\cline { 2 - 3 } $27-46$ & $\mathrm{n}$ & $\%$ \\
$47-74$ & 57 & 34.5 \\
Total & 140 & 44.2 \\
& & 37.6 \\
& At Least One Deep Pocket $\ddagger$ \\
$27-46$ & 21 & 8.3 \\
$47-74$ & 25 & 20.8 \\
Total & 46 & 12.4 \\
\hline
\end{tabular}

${ }^{*}$ Categories are not mutually exclusive.

$+4-5 \mathrm{~mm}$ deep.

$\ddagger$ Equal to or deeper than $6 \mathrm{~mm}$. 
FIGURE 1

Number of Individuals with Deep Pockets by Number of Tooth Sites Affected

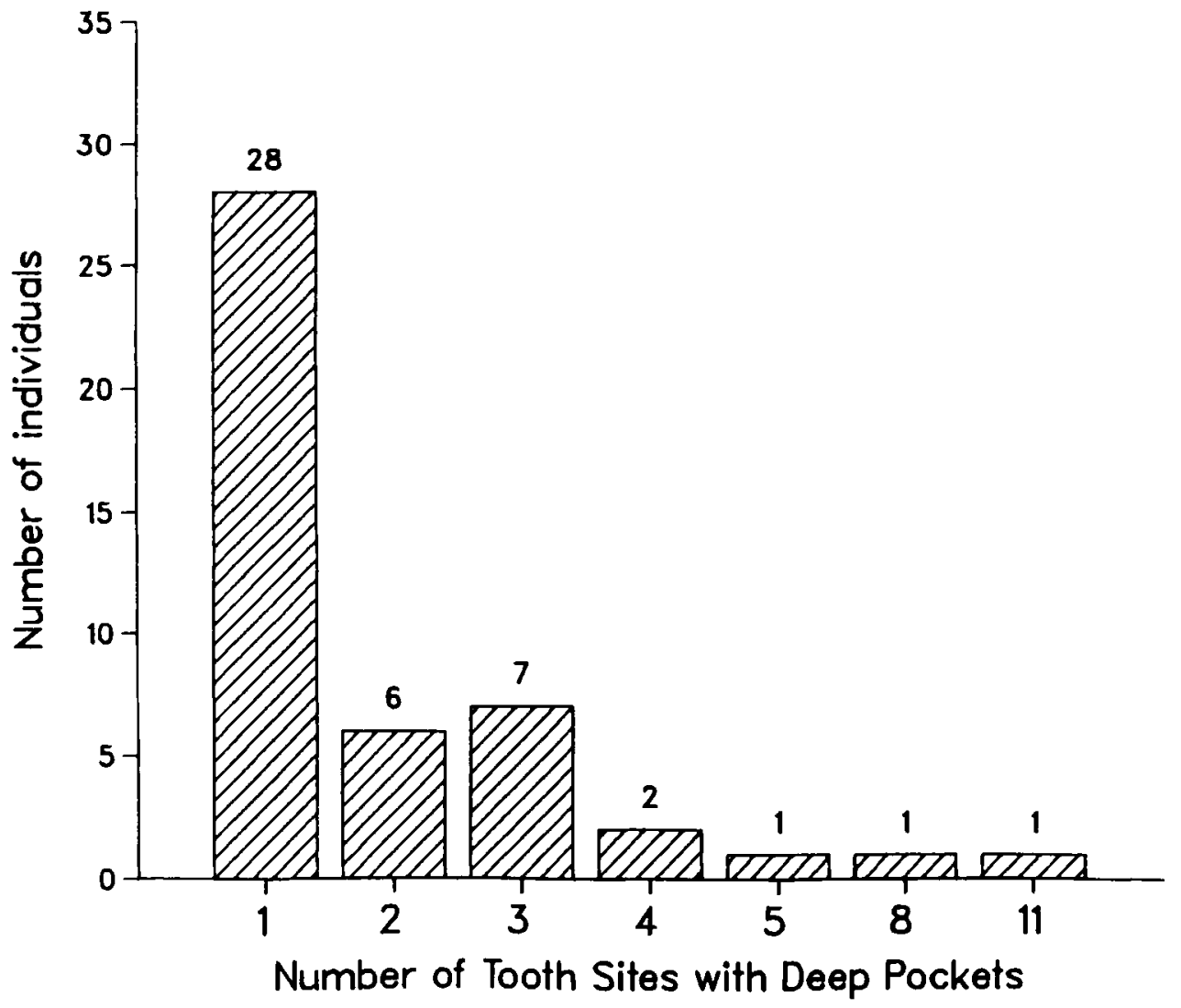

FIGURE 2

Mean Number of 0-3 and 4-5 mm Pockets in Those with at Least One Deep Pocket

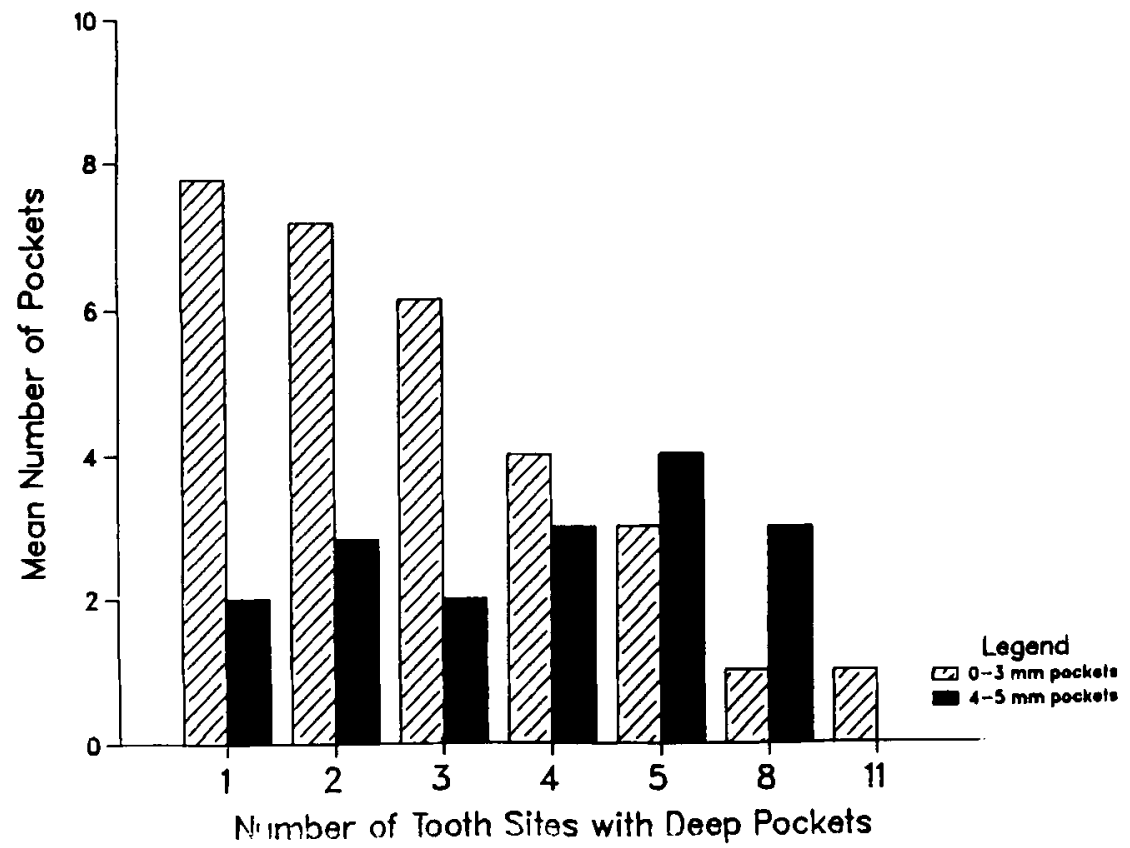


TABLE 5

Mean Number of Teeth per Person (Out of Six Index Teeth) with No Calculus, with Supragingival Calculus Only, with Subgingival Calculus, and with Plaque, by Pocket Depth, Lordsburg and Deming, New Mexico, 1984

\begin{tabular}{lcc}
\hline & \multicolumn{2}{c}{ Presence of Deep Pockets } \\
\cline { 2 - 3 } & None & Present \\
\hline No calculus & 0.22 & 0.06 \\
Supragingival calculus only & 0.42 & $0.06^{*}$ \\
Subgingival calculus & 5.20 & 5.40 \\
Number of teeth with plaque & 1.93 & $3.82 \dagger$ \\
\hline
\end{tabular}

*Mean numer of teeth with only supragingival calculus is higher in those without deep pockets, $p<0.04$.

tMean number of teeth with plaque is higher in those with deep pockets, $\mathrm{p}<0.001$.

pockets had gingival bleeding. The mean number of tooth sites for those with deep pockets was 4.28 , while for those without deep pockets it was 2.21 (difference was statistically significant, $\mathrm{p}<0.0001$ ).

Findings from the logistic regression model. The results of logistic regression model, which associates the probability of concurrently having deep pockets with different risk factors, are presented in Table 7. The significant correlates with presence of deep pockets were age and the number of teeth with plaque. Presence of supragingival and subgingival calculus and gingival bleeding all failed to remain significantly associated with the probability of having deep pockets when age and the number of teeth with plaque were accounted for. Age and the number of teeth with plaque only explained 10.5 percent of the variability in the prevalence of deep pocketing.

\section{Discussion}

The target population in this study was all residents of Lordsburg and Deming, New Mexico, who were born and lived for at least the first six years of their lives in their respective communities. It was estimated from US Census data, and estimates of the local organizers, that more than 200 residents over 30 years of age may have been eligible to participate. Selection of these individuals was achieved using local recruiters who contacted all known eligible residents in both communi-
TABLE 7

Logistic Regression Coefficients ( \pm SEM) of the Probability of Having at Least One Pocket Deeper than Six mm Associated with Residence, Gender, Education Status, Age, Number of Teeth with Plaque, and Number of Tooth Sites with Gingival Bleeding. Lordsburg and Deming, New Mexico, 1984.

\begin{tabular}{lcl}
\hline Variable name & B & SEM \\
\hline City & 0.27 & 0.39 \\
Gender & -0.53 & 0.34 \\
Education & -0.10 & 0.18 \\
Aget & 1.04 & $0.36^{*}$ \\
Racef & 0.40 & 0.45 \\
Number of teeth with & 0.30 & $0.09^{*}$ \\
$\quad \begin{array}{l}\text { plaque** } \\
\quad \text { gingival bleeding** }\end{array}$ & 0.12 & 0.06 \\
\hline
\end{tabular}

*Significantly different from zero with more than five percent confidence.

tAge in years was coded into groups: $1=27-46$ and $2=47-74$.

tRace was coded: $1=$ Hispanic, $2=$ other

${ }^{* *}$ Total number of teeth was six; tooth sites was 12 .

ties. As might be expected, the results of this study should be interpreted with the caveat that data were collected from individuals who may not represent any other population group outside their own communities.

The use of six index teeth to estimate the mean loss of periodontal attachment or Periodontal Disease Index scores has been reported to represent validly the status of the mouth $(15,16)$. But the limited data presented to support this argument did not consider that deep pocketing may only be present around a few teeth and, thus, when index teeth are used rather than all teeth present in the mouth in an analysis similar to the one presented here, the prevalence of deep pocketing may be underestimated. Unpublished analysis of loss of periodontal attachment data collected in 1958 from 1,976 New Mexicans aged 17 to 46 years indicates that the percentages of individuals with advanced loss of periodontal attachment (greater than six $\mathrm{mm}$ ) could be underestimated by about 50 percent in those aged 17 46. (Results of the analysis can be obtained from the authors.) These finding are similar to those of Ainamo and Ainamo (17).

TABLE 6

Number and Percent of Individuals with One or More Pockets Greater than Six mm by Status of Gingival Bleeding on Facial and Mesiofacial Sites of Six Index Teeth of Ramfjord (5). Residents of Lordsburg and Deming, New Mexico, 1984.

\begin{tabular}{|c|c|c|c|c|}
\hline \multirow[b]{3}{*}{ Presence of Deep Pockets } & \multicolumn{4}{|c|}{ Gingival Bleeding (GB) } \\
\hline & \multicolumn{2}{|c|}{$\begin{array}{l}\text { None of the Index } \\
\text { Teeth had GB }\end{array}$} & \multicolumn{2}{|c|}{$\begin{array}{l}\text { At Least One Index } \\
\text { Tooth Site Had GB }\end{array}$} \\
\hline & $n$ & $\%$ & $n$ & $\%$ \\
\hline $\begin{array}{l}\text { None } \\
\text { At least one tooth site with a deep pocket }\end{array}$ & $\begin{array}{r}98 \\
8\end{array}$ & $\begin{array}{l}30.1 \\
17.4\end{array}$ & $\begin{array}{r}228 \\
38\end{array}$ & $\begin{array}{l}69.9 \\
82.6\end{array}$ \\
\hline
\end{tabular}


Hence, an inflation of the figures presented in this paper will result in a prevalence of deep pocketing of 25 percent instead of 12.4 percent, and a mean number of tooth sites with deep pocketing equal to 0.50 instead of 0.25 . Even after this correction for the possible underestimation, about three-fourths of the adults in the two communities still remain without any advanced periodontal destruction.

The results of the study reported here show that only 8.3 percent and 20.8 percent of the adults aged $27-46$, and 47-74, respectively, had at least one deep pocket, and 89.1 percent of those with deep pockets had fewer than four tooth sites affected. These percentages are higher than those reported by Beck and colleagues (1) for similar age groups, Reddy and others (2) for South Africans over the age of 15 , and approach those reported by Markkanen and colleagues (5) in Finnish adults aged 30 years and over. Similar data on prevalence of deep pocketing in residents of the southwestern region of the United States could not be found. The Sheiham and Striffler (18) analysis of data, gathered from 1,976 young adults residing in New Mexico in 1958, showed that Hispanics and American Indians had more severe periodontal disease (based upon loss of periodontal attachment measurements) than others and that the

\section{... when index teeth are used rather than all teeth present in the mouth in an analysis similar to the one presented here, the prevalence of deep pocketing may be underestimated.}

number of years of schooling was positively associated with the severity of periodontal disease. The data presented in this study may suggest that the relatively higher prevalence of deep pocketing, when compared to the data from Beck and colleagues (1), may be because of the higher prevalence of plaque, calculus, and gingival bleeding in the examinees. In the Iowa survey (1), about 63-76 percent of those examined had at least one index tooth with calculus, and about 38-47 percent had teeth with gingival bleeding after probing (prevalence of plaque was not reported) (1). In the study reported here, 67 and 98 percent of those examined had at least one tooth with plaque and calculus, respectively. Despite this high percentage of persons with plaque and calculus, about 80 percent of those aged 47 to 74 years had no demonstrable deep pockets.

In 60 percent of those with deep pockets, only one tooth site was affected and about 50 percent of the tooth sites in those individuals had no pockets. The data depicted in Figure 2 may support the thesis suggested by Socransky and others (19) that deep pocketing occurs at specific tooth sites within the mouth while other tooth sites within the same mouth are either free from periodontal disease or mildly affected.

An important correlate with the presence of deep pocketing in this study was the presence of plaque, while the presence of supragingival or subgingival calculus was not associated with deep pocketing. Presence of plaque alone only explained 8.3 percent of the variability in the prevalence of deep pocketing; plaque and age together explained only 10.5 percent of the variability. This analysis shows that while the presence of plaque was an important risk factor for deep pocketing, about 90 percent of the variability in the prevalence of deep pocketing remained unexplained.

The planning of public health programs to prevent and control periodontal disease will require answering a number of yet unanswered questions about the distribution and risk factors associated with periodontal disease. What is needed first is the precise definition and measurement of each condition (gingivitis; shallow, medium, and deep pockets). The use of measurement criteria that lump gingivitis and periodontitis together may provide useful data for planning and estimation of treatment needs. The most important issue that public health programmers need to answer is just when a periodontal condition (gingivitis or periodontitis) is to be considered a health problem that will require commitment of personnel and funds. This limited study has shown that deep periodontal destruction will be found in one-fourth of the population and on average will affect one to two teeth per individual. If these affected teeth are more prone to be lost as a result of loss of periodontal support, then it will be necessary to include screening for presence of deep pocketing in a public health program. Identification and referral for treatment could be one of the objectives of a public health program to control and prevent periodontal disease.

\section{Conclusions}

The results of this analysis show that only 12.4 percent of those over age 27 years had deep pocketing on one or more of the six index teeth; when present, the deep pockets usually involved only one or two of the index teeth, rather than presenting a generalized condition. Only five persons had deep pockets on four or more of the 12 sites measured. These findings were in a population that had received little dental care, and where oral hygiene status and gingival conditions were extremely poor.

About seven percent of all tooth sites examined had shallow pockets (4.0-5.0 $\mathrm{mm}$ in depth); these pockets occurred in 37.6 percent of persons examined. About 2.1 percent of all tooth sites examined had deep pockets and were clustered in 12.4 percent of the adults. Presence of plaque was the most important risk factor associated with deep pocketing; however, about 90 percent of the variability in the prevalence of deep pocketing was not explained by presence of plaque, calculus, age, education status, gender, ethnic group, or residence in either an optimally fluoridated or a high fluoride ( 3.8 ppm) community.

\section{Acknowledgments}

The authors thank Dr. Edith C. Morrison, Department of Periodontics, School of Dentistry, the University of Michigan, for assistance in training the examiners to measure pocket depth and loss of periodon- 
tal attachment. The local coordinators, Ms. Maura Rico in Lordsburg, and Mrs. Lucretia Jones in Deming, New Mexico, along with numerous others in each community, performed magnificently in the critical task of identifying and recruiting the subjects for the study. Without their considerable effort and organizational skills, the study would have been impossible. They also thank Mr. Juan Garcia and Mr. John Trumbull of the New Mexico Health and Environment Department for their help during the project.

\section{References}

1. Beck JD, Lainson PA, Field HM, Hawkins BF. Risk factors for various levels of periodontal disease and treatment needs in lowa. Community Dent Oral Epidemiol 1984 Feb;12:17-22.

2. Reddy I, Parker JR, Africa CW, Stephen LXG. Prevalence and severity of periodontitis in a high fluoride area in South Africa. Community Dent Oral Epidemiol 1985 Apr;13:108-12.

3. Plasschaert AJM, Flomer T, Van Den Heuvel J, Jansen J, Van Opijnen L, Wouters SLJ. An epidemiologic survey of periodontal disease in Dutch adults. Community Dent Oral Epidemiol 1978 Mar;6:65-70.

4. Hughes JT, Rozier RG, Ramsey DL. Natural history of dental disease in North Carolina 1976-77. Durham, NC: Carolina Academic Press, 1982

5. Markkanen H, Rajala M, Paunio K. Periodontal treatment need of the Finnish population aged 30 years and over. Community Dent Oral Epidemiol $1983 \mathrm{Feb} ; 11: 25-32$.

6. Hugoson A, Jordan T. Frequency distribution of individuals aged 20-70 years according to severity of periodontal disease. Community Dent Oral Epidemiol 1982 Aug;10:187-92.

7. Ramfjord SP. Indices for prevalence and incidence of periodontal disease. J Periodontol 1959 Jan;30:51-9.

8. Gaengler P. Prevalence and distribution of gingivitis, periodontitis and missing teeth in adolescents and adults according to GPM/
T index. Community Dent Oral Epidemiol 1984 Aug;255-9.

9. Eklund SA, Ismail AI, Burt BA, Calderone JJ. Effects of severe dental fluorosis on the oral health of adults. Ann Arbor: University of Michigan, 1985, 106 pp. (A copy of the report can be obtained from the authors.)

10. Dean HT. The investigation of physiological effects by the epidemiological method. In: Moulton FR, ed. Fluorine and dental health. Washington, DC: American Association for Advancement of Science, 1942:23-71.

11. Ainamo J, Bay I. Problems and proposal for recording gingivitis and plaque. Int Dent J 1975 Dec;25:229-35.

12. Lindhe J. Textbook of clinical periodontology. Philadelphia: WB Saunders, 1984:300.

13. Glantz SA. Primer of biostatistics. New York: McGraw-Hill, 1981:105,117.

14. Kleinbaum DG, Kupper LL, Morgenstern H. Epidemiologic research. Principles and quantitative methods. Belmont, CA: Lifetime Learning Publications, 1982.

15. Jamison HC. Prevalence and severity of periodontal disease in a sample of a population. Ann Arbor: University of Michigan, 1960. 153 pp. Dissertation.

16. Gettinger G, Patters MR, Testa MA, Löe H, Anerud A, Boysen H, Robertson PB. The use of six selected teeth in population measures of periodontal status. J Periodontol 1983 Mar;54:155-9.

17. Ainamo J, Ainamo A. Partial indices as depictors of periodontal status and treatment needs [Abstract]. J Dent Res 1982 Mar$; 61$ (Spec Iss):221. (The full manuscript could not be located.)

18. Sheiham A, Striffler DF. A comparison of four epidemiological methods of assessing periodontal disease. J Periodont Res 1970;5:148-54.

19. Socransky SS, Haffajee AD, Goodson JM, Lindhe J. New concepts of destructive periodontal disease. J Clin Periodontol 1984 Jan;11:21-32. 